\title{
Letter to the editor regarding the article "Evaluation of pain perception associated with use of the magnetic-end ureteric double-J stent for short-term ureteric stenting"
}

\author{
Sridhar Panaiyadiyan ${ }^{1}\left[\right.$ [ Prabhjot Singh ${ }^{1} \cdot$ Brusabhanu Nayak $^{1}$
}

Received: 22 April 2018 / Accepted: 24 April 2018 / Published online: 11 May 2018

๑) Springer-Verlag GmbH Germany, part of Springer Nature 2018

\section{Dear Editor,}

We recently reviewed the article by Sevcenco et al. [1] in our journal club. The authors described a novel magnetic end ureteral stent retrieved by a special catheter tip with a complementary magnetic end. The magnetic ureteral stent retrieval with the special catheter was compared with flexible cystoscopic retrieval of the standard ureteral stent for pain perception. The results of their data showing significantly less pain perception with magnetic ureteral stent retrieval were appealing for implementation of such stents on regular basis. But, there seem to be some queries to be clarified.

Altarac et al. describe a similar stent with a permanent magnet on the distal part. The retrieval device was a Nelaton catheter with a magnet at the tip [2]. However, removal was not always successful due to lack of mobility of the catheter and decoupling of the magnets [3]. Hence, it is worth discussing whether the magnetic tip stents were retrieved in the first attempt in all patients? Also, how many times the special catheter needed to be re-inserted while it may induce urethral trauma as the tip contains complementary magnet tip and not the blunt tip as of Foley's catheter. Finally, we would recommend the authors to give some insights regarding bladder fill amount before inserting the special catheter as it may influence the position of the bladder coil of the stent depending on the amount of urine in the bladder. We look forward to the author's reply to clarify our queries.

\section{Compliance with ethical standards}

Conflict of interest The authors declare that they have no conflicts of interests.

\section{References}

1. Sevcenco S, Eredics K, Lusuardi L, Klingler HC (2018) Evaluation of pain perception associated with use of the magnetic-end ureteric double-J stent for short-term ureteric stenting. World J Urol 36:475-479. https://doi.org/10.1007/s00345-017-2146-x

2. Altarac S, Vražić M (2012) A new type of ureteral stent will facilitate stent removal. Eur Urol 61:225-226. https://doi.org/10.1016/j. eururo.2011.08.075

3. Rassweiler MC, Michel MS, Ritter M, Honeck P (2017) Magnetic ureteral stent removal without cystoscopy: a randomized controlled trial. J Endourol 31:762-766. https://doi.org/10.1089/ end.2017.0051

This comment refers to the article available at https://doi. org/10.1007/s00345-017-2146-x.

Sridhar Panaiyadiyan

sridharsoul@gmail.com

Prabhjot Singh

drprabhjotsingh@gmail.com

Brusabhanu Nayak

brusabhanu@gmail.com

1 Department of Urology, All India Institute of Medical

Sciences, New Delhi 110029, India 